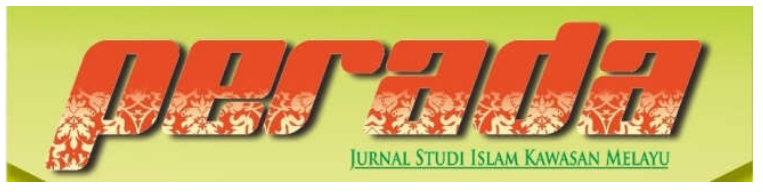

Perada: Jurnal Studi Islam Kawasan Melayu

P-ISSN 2656-7202 E-ISSN 2655-6626

Volume 2 Nomor 1, Januari-Juni 2019

\title{
PENGARUH INTERNET TERHADAP PERKEMBANGAN PSIKOLOGIS SISWA MADRASAH TSANAWIYAH DI TANJUNGPINANG
}

\author{
Ediyansyah \\ STAIN Sultan Abdurrahman Kepulauan Riau \\ ediyansyah.mpdi@gmail.com
}

\begin{abstract}
ABSTRAK
Media internet membuat hubungan yang jauh menjadi dekat, cepat dan mudah. Ini memberikan banyak manfaat, beberapa dapat memberikan manfaat baik dan buruk, manfaat kebaikan jika digunakan untuk mencari informasi tentang pembelajaran dan kejahatan jika digunakan untuk pornografi, informasi tentang kekerasan, dan lainnya yang negatif termasuk bahaya psikologis karena kecanduan internet. Sumber daya manusia dalam penelitian ini adalah siswa MTS di Tanjung Pinang. Tujuan dari penelitian ini adalah untuk mengetahui pengaruh media internet terhadap perkembangan psikologis siswa MTS di Tanjung Pinang. Ini adalah penelitian kualitatif. Teknik pengumpulan data menggunakan kuesioner skala likert. Analisis menggunakan teknik analisis korelasi dan analisis regresi berganda dengan uji prasyarat, analisis korelasi momen produk dan regresi berganda. Besarnya koefisien korelasi antara variabel $X$ dan $Y$ adalah sama dengan 0,201> 0,1654. Kesimpulan dalam penelitian ini didasarkan pada hasil yang diperoleh bahwa ada pengaruh antara media internet terhadap perkembangan psikologis siswa MTS di Tanjung Pinang.
\end{abstract}

Abstract: The internet media makes a distant relationships be close, fast and easy. This provides many benefits, some can provide good and bad benefits, goodness benefits if used to find information about learning and badness if used for pornography, information about violence, and others that are negative including psychological endanger due to the internet addiction. The human resources in this research are MTS students in Tanjung Pinang. The purpose of these research was to determine the influence of internet media on the psychological development of MTS students in Tanjung Pinang. This is qualitative research. The technique of collecting data using the Likert scale questionnaire. Analysis using correlation analysis techniques and multiple regression analysis with prerequisite tests, product moment correlation analysis and multiple regression. The magnitude of the coefficient correlation between variable $X$ and $Y$ is equal to $0.201>0.1654$. The conclusions in this reaserch are based on the results obtained that there is an influence between internet media on the development psychological of MTS students in Tanjung Pinang. 


\section{PENDAHULUAN}

Dalam

perkembangannya, kemajuan dunia ICT telah memberikan pengaruh yang sangat luar biasa besar terhadap semua aspek kehidupan kita. Saat ini kita sering melihat begitu banyaknya orang menggunakan internet di setiap aktivitasnya sehingga orang meng-anggap bahwa hidup kita tidak dapat dipisahkan lagi dari internet, termasuk yang menggunakan dari para pelajar. ${ }^{1}$ Para pelajar yang memanfaat-kan media internet untuk pendidikan dapat melakukannya dalam berbagai bentuk sesuai dengan fungsinya dalam pendidikan. Sekolah ataupun lembaga pendidikan seyogyanya harus bisa secepatnya memanfaatkan fungsi IT dan TIK dalam setiap proses kegiatannya sehingga menjadi suatu keharusan yang tidak boleh dielakan lagi. Untuk program atau aplikasi yang berkaitan dengan TIK sudah banyak dijual dipasaran dan siap untuk digunakan oleh sekolah atau masyarakat secara luas dan optimal untuk kebutuhan di dunia pendidikan. Realitasnya, saat ini TIK telah berfungsi sebagai alat bantu dalam proses pembelajaran, fasilitas pendidikan, gudangnya ilmu, standar kompe-tensi, penunjang administrasi, alat bantu bagi manajemen sekolah, dan juga sebagai infra-struktur pendidikan.

1 H Muhammad Yusuf Rahim, 'Pemanfaatan ICT Sebagai Media Pembelajaran Dan Informasi Pada UIN Alauddin Makassar', 6 (2011), <https://doi.org/10.24252/.v6i2.1408>.
Pengaruh media internet bagi pelajar saat ini dapat dirasakan berdasarkan cara pengguna-annya. Ada pengaruh positif bagi para pelajar yang sifatnya memang tidak mutlak karena penilaiannya secara personal tidak sama. Namun umumnya, internet bagi pelajar berpengaruh positif adalah pada bagian informasinya. Dahulu jika informasi/ilmu pengetahuan itu hanya ada jika kita mencarinya pada sebuah buku ataupun juga ketika kita bertemu dengan orang cerdik pandai (pintar), akibatnya dalam penyebaran ilmu dan juga informasi menjadi mahal, lambat, dan tidak banyak. Maka dalam penggunaan media internet, para pelajar bida mendapatkan dan mengetahui banyak hal hanya dengan mengetikkan atau memasukan kata kunci yang ingin dicari olehnya pada suatu search enginel mesin pencari (seperti yang umumnya banyak dipakai seperti google.com dan yahoo.com). Tidak berapa lama kemudian, maka daftar halaman yang sesuai menurut kata kuncinya tersebut akan muncul dalam jumlah yang sangat banyak. Sehingga para pelajar mendapatkan informasi yang mereka inginkan, seperti tugas-tugas PR dan pelajaran sekolah.

Pemerintah memiliki tanggung jawab besar terhadap pendidikan tetapi tanggung-jawab ini harus juga diberikan di keluarga, sekolah dan masyarakat. Tanggung-jawab pemerintah ini dibuktikan dalam menyediakan kebutuhan terutama sarana dan prasarana serta fasilitas pendidikan, sedangkan 
tanggung jawab sekolah ada pada pengelolaannya serta bagaimana melakukan bimbingan kepada para peserta didik. ${ }^{2}$ Kemudian tanggung-jawab masyarakat dibutuhkan peran aktifnya dalam menyukseskan program pemerintah tersebut, baik itu yang berbentuk pengunaan sekolah maupun yang berbentuk pembinaan masyarakat. Sedangkan tempat pertama anak dalam mendapatkan pendidikan adalah keluarga. $^{3}$ Di keluarga jugalah yang melakukan pengawasan anak diluar sekolah. Tanggung jawab pendidikan di keluarga adalah tugas orang tua, dimana orang tua memegang perananan penting dalam meningkatkan minat belajar anak. Keluarga yang sangat besar sekali pengaruhnya dibandingkan dengan lingkungan sekolah dan masyarakat, maka hendaknya keluarga selalu memberikan dorongan kepada anak agar supaya lebih giat belajar dan membimbingnya kearah yang positif. ${ }^{4}$

Seseorang pelajar itu memiliki minat belajar yang berubah-ubah atau tidak stabil. Mereka itu hanya perlu diarahkan kepada sesuatu pilihan-pilihan dan dalam perkembang-annya sangat ditentukan oleh pertama faktor internal, maksudnya adalah yang ada didalam diri seseorang, baik itu jasmaninya maupun

${ }^{2}$ Sheilla Chairunnisyah Sirait, 'Tanggung Jawab Pemerintah untuk Memberikan Pendidikan Kepada Anak Terlantar dalam Perspektif UndangUndang Perlindungan Anak' <https://doi.org/10.31219/osf.io/75tp2>.

3 Hasbi Wahy, 'Keluarga Sebagai Basis Pendidikan Pertama dan Utama', Jurnal Ilmiah Didaktika, $\quad 12.2 \quad$ (2012) <https://doi.org/10.22373/jid.v12i2.451>.

4 M. Roqib, Ilmu Pendidikan Islam: Pengembangan Pendidikan Integratif Di Sekolah, Keluarga Dan Masyarakat (Yogyakarta: LKiS, 2009), h.38. rohani, juga fisik maupun phisikisnya, sedang-kan yang kedua adalah faktor eksternal maksud-nya faktor-faktor di luar dari individunya seperti sekolah, keluarga, dan masyarakat. Jadi di perlukan minat dari siswa yang akan memberi-kan pengaruh yang besar dalam proses pembelajaran, sehingga seorang anak yang aktif dan maupun pasif dalam proses pembelajaran sangat tergantung terhadap ada tidaknya minat belajarnya.

Dalam suatu lingkungan fisik maupun lingkungan sosial, manusia harus hidup dengan saling memberikan hubungan timbal-balik, sehingga akan saling mempengaruhi antara manusia dengan lingkungannya. Saat ini ternyata perkembangan lingkungan telah memberikan perannya dan juga pengaruh yang dalam terhadap aktivitas belajar bagi para siswa. Banyak perilaku tersebut tercermin dalam setiap tindakan pelajar yang dipengaruhi oleh lingkungannya sehingga akan membentuk pola pikir psikologi para pelajar. Para pelajar melakukan berbagai tindakan yang didasari oleh pembentukan kepribadiaan yang melatar-belakangi perkembangan lingkungan tempatnya bersosialisasi, walaupun pada intinya perkembangan psikologi sosial tergantung kepada bagaimana para pelajar memberikan respon terhadap lingkungannya.

Lingkungan di sekolah merupakan tempat terlaksananya proses belajar dalam mendidik para peserta didik, sehingga dikatakan bahwa sekolah adalah tempat untuk mendapatkan pendidikan formal. Pemerintah menganggap pendidikan adalah sarana terpenting untuk mewujudkan kemajuan bangsa dan negara. Melalui pendidikan juga dapat 
terbentuk suatu proses budaya yang bertujuan meningkatkan harkat dan martabat manusia. Untuk itulah sangat diperlukan pencapaian kompetensi di semua bidang baik dibidang ekonomi, sosial maupun budaya, agar generasi muda bangsa bisa bersaing dan tetap bisa bertahan di era globalisasi sekarang ini. Pemerintah dalam upayanya untuk meningkatkan kompetensi manusia atau sumber daya manusia. Pemerintah menganggap salah satu faktor penting adalah mutu pendidikan, terutama pada mutu pendidikan sekolah. Sehingga mutu pendidikan dalam peningkatannya akan menciptakan manusia indonesia yang nantinya mampu bersaing nantinya. Dalam memperlancar peningkatan mutu pendidikan sangat dipengaruhi pada suatu lingkungan belajar yang efektif dan sarana-prasarana belajar yang memadai.

Efektivitas dalam suatu lingkungan belajar akan berubah menjadi produktif. Produktivitas sebuah lingkungan belajar harus dirancang atau dibangun dengan baik untuk membantu pelajar dalam meningkatkan produktivitas belajar mereka sehingga hasil belajar mengajar yang maksimal dapat dicapai. Efektivitas pada suatu lingkungan belajar akan bisa membuat pelajar menjadi lebih produktif, hal ini dapat digambarkan bahwa para pelajar akan mudah dalam berpikir, berkreasi, juga mampu belajar secara aktif, karena mendapatkan dukungan dari lingkungan belajarnya sehingga muncul ketertarikan dan kenyamanan saat berlangsung proses belajar mengajar.

Keberhasilan pendidikan pada seseorang itu dapat dipengaruhi oleh faktor-faktor seperti kecerdasan anak, bakat anak, kegiatan belajar dan lingkungan di sekolah dan yang lainnya bahwa ada juga yang mempengaruhi pendidikan pada seorang anak termasuk dari dalam lingkungan keluarga, sekolah atau masyarakat. Lingkungan sangat besar pengaruh terhadap perubahan-perubahan sifat, sikap, dan perasaan dan juga terhadap pemikiran anak didik, yang berakibat dapat menciptakan dan memberikan pendidikan yang buruk ataupun yang baik terhadap perkembangan-perkembangannya.

Berdasarkan uraian diatas maka peneliti tertarik untuk melakukan analisis pengaruh media internet terhadap perkembangan psikologis siswa Madrasah Tsanawiyah di Tanjung Pinang, pokok masalah mengenai pengaruh dan problem psikologis siswa yang menggunakan internet terhadap pendidikannya.

\section{METODE PENELITIAN}

Penelitian ini menggunakan penelitian kualitatif dengan variabel bebasnya adalah media internet dan variabel terikatnya adalah perkembangan psikologis siswa. Penelitian yang dilakukan merupakan penelitian hubungan/ korelasional yang bertujuan untuk mencari hubungan/pengaruh variabel bebas terhadap variabel terikat. Pada penelitian ini pengumpul-an datanya termasuk penelitian survey dimana dilakukan survey dahulu untuk menggumpulkan data ataupun informasi tentang populasi yang besar dengan menggunakan sampel yang relatif sedikit. ${ }^{5}$

Keseluruhan subyek penelitian atau populasi penelitian ini adalah siswa di

5 Nana Syaodih Sukamadinata, Metode Penelitian Pendidikan (Bandung: Remaja Rosadakarya, 2007), h.82. 
MTS di Tanjung Pinang yang berjumlah 667 siswa maka sampel yang digunakan berjumlah 100 siswa yang berdasarkan Suharsimi Arikunto diambil $15 \%$ sampel terhadap populasi. ${ }^{6}$

Metode kuesioner digunakan oleh peneliti sebagai alat untuk mengumpulkan data. Teknik pengumpulan data dengan cara metode kuesioner ini dilakukan dengan memberi beberapa pertanyaan kepada responden untuk dijawab yang bersifat tertulis. Maka digunakan kuisioner atau angket untuk memperoleh data tentang pengaruh media internet terhadap perkembangan psikologis siswa. ${ }^{7}$

Dalam penelitian ini instrumennya uji coba dengan membagi menjadi dua yaitu untuk angket dan tes. Untuk angket mengunakan uji validitas dengan menggunakan ujia validitas (construct validity) dan uji reliabilitas dengan cara internal consistency. Untuk uji test dilakukan dengan dengan uji validitas menggunakan pearson product moment corelation, pengujian reliabilitas test dengan rumus Cronbach's Alpha $(\propto)$, daya pembeda soal dan perhitungan tingkat kesukaran.

Untuk teknik analisis datanya dengan melakukan (1) analisis uji prasyarat meliputi uji normalitas, uji linieritas, multikolinieritas. (2) hipotesis pertama dan kedua dengan menggunakan product moment corelation, (3) hipotesis tiga dengan menggunakan regresi linier sederhana.

${ }^{6}$ Suharsimi Arikunto, Prosedur Penelitian: Suatu Pendekatan Praktik (Jakarta: Rineka Cipta, 2013), h.108.

Sugiono, Metode Penelitian PendidikanPendekatan Kuantitaif, Kualitatif Dan R\&D (Bandung: Alfabeta, 2008).

\section{HASIL DAN PEMBAHASAN}

\section{Perkembangan psikologis siswa (Y)}

Hasil pengukuran terhadap perkem-bangan psikologis siswa diperoleh rentangan skor terendah 43 dan skor tertinggi 78 terdiri dari 20 soal kuesioner tentang perkembangan psikologis siswa dengan skor jawaban per item terendah 1 dan tertinggi 5. Rata-rata skor kuesioner sebesar 62,81, artinya rata-rata perkembangan psikologis siswa adalah baik karena besarnya rata-rata perkembangan psikologis siswa berada mendekati skor ideal yaitu 63 dengan penyimpangan (std deviation) sebesar 6,882. Median sebesar 63,00 menunjukkan nilai tengah skor jawaban dan mode sebesar 63 menunjukkan skor yang sering muncul adalah 63 .

Statistics

\begin{tabular}{|l|c|c|}
\hline \multicolumn{2}{|c|}{ Perkembangan Psikologis Siswa (Y) } \\
\hline \multirow{2}{*}{$\mathrm{N}$} & Valid & 100 \\
\cline { 2 - 3 } & Missing & 0 \\
\hline Mean & 62.81 \\
\hline Std. Error of Mean & .688 \\
\hline Median & 63.00 \\
\hline Mode & 63 \\
\hline Std. Deviation & 6.882 \\
\hline Variance & 47.368 \\
\hline Range & 35 \\
\hline Minimum & 43 \\
\hline Maximum & 78 \\
\hline Sum & 6281 \\
\hline
\end{tabular}

\section{Pengaruh media internet (X)}

Hasil pengukuran terhadap media internet yang berjumlah 20 butir angket diperoleh rentangan skor terendah 20 dan skor tertinggi 88 terdiri dari 20 soal kuesioner tentang media internet dengan 
skor jawaban per item terendah 1 dan tertinggi 5. Rata-rata skor kuesioner sebesar 58,16 yang berarti rata-rata media internet adalah baik, hal ini dikarenakan rata-rata skor berada di atas skor ideal yaitu sebesar 58, dengan penyimpangan (std deviation) sebesar 13,424. Median sebesar 58,00 menunjukkan nilai tengah skor jawaban dan mode sebesar 53 menunjukkan skor yang sering muncul adalah 53, selengkapnya dapat dibuat grafik histogram sebagai berikut.

Statistics

\begin{tabular}{|l|c|c|}
\hline \multicolumn{2}{|c|}{ Pengaruh Media Internet (X) } \\
\hline \multirow{2}{*}{$\mathrm{N}$} & Valid & 100 \\
\cline { 2 - 3 } & Missing & 0 \\
\hline Mean & 58.16 \\
\hline Std. Error of Mean & 1.342 \\
\hline Median & 58.00 \\
\hline Mode & 53 \\
\hline Std. Deviation & 13.424 \\
\hline Variance & 180.196 \\
\hline Range & 68 \\
\hline Minimum & 20 \\
\hline Maximum & 88 \\
\hline Sum & 5816 \\
\hline
\end{tabular}

Uji analisis data dengan uji asumsi klasik

\section{Normalitas}

Pengujian normalitas data menggunakan analisis Kolmogorof Smirnov. Pada distribusi datanya apabila signifikansi nilai dari Kolmogorof Smirnov $>0,05$ adalah normal. Hasil perhitungan Kolmogorof Smirnov didapatkan nilai signifikansi 0,059 yang ternyata lebih besar dari 0,05 maka distribusi residual model regresi ini adalah normal.

Tabel. Hasil Uji Normalitas

\begin{tabular}{|l|l|c|}
\hline \multicolumn{2}{|c|}{$\begin{array}{c}\text { One-Sample Kolmogorov-Smirnov } \\
\text { Test }\end{array}$} \\
\hline \multicolumn{2}{|c|}{} & $\begin{array}{c}\text { Unstandardize } \\
\text { d Residual }\end{array}$ \\
\hline $\mathrm{N}$ & 100 \\
\hline $\begin{array}{l}\text { Normal } \\
\text { Parameters } \\
\text { b }\end{array}$ & Mean & .0000000 \\
\cline { 2 - 3 } & $\begin{array}{l}\text { Std. } \\
\text { Deviatio } \\
\text { n }\end{array}$ & 6.74200788 \\
\hline $\begin{array}{l}\text { Most } \\
\text { Extreme } \\
\text { Differences }\end{array}$ & Absolute & Positive \\
\cline { 2 - 3 } & Negative &. .060 \\
\hline Test Statistic & .087 \\
\hline Asymp. Sig. (2-tailed) & $.059^{c}$ \\
\hline
\end{tabular}

a. Test distribution is Normal.

b. Calculated from data.

c. Lilliefors Significance Correction.

\section{Heteroskedastisitas}

Hasil analisis terhadap uji heterokedas-tisitas dengan LM besarnya $\left(\mathrm{R}^{2}\right) \times \mathrm{N}$ sebesar 4 yang berarti nilai ini lebih besar dari chi square $\left(\mathrm{x}^{2}\right)$ sebesar 0,961 maka menunjukkan gejala heterokedastisitas.

Tabel. Hasil uji regresi

\begin{tabular}{|c|c|c|c|c|}
\hline \multicolumn{5}{|c|}{ Model Summary $^{\mathbf{b}}$} \\
\hline Model & $\mathrm{R}$ & $\begin{array}{c}\mathrm{R} \\
\text { Square }\end{array}$ & $\begin{array}{c}\text { Adjusted } \\
\text { R Square }\end{array}$ & $\begin{array}{c}\text { Std. Error } \\
\text { of the } \\
\text { Estimate }\end{array}$ \\
\hline 1 & $.201^{\mathrm{a}}$ & .040 & .031 & 6.776 \\
\hline
\end{tabular}

a. Predictors: (Constant), Pengaruh Media Internet $(\mathrm{X})$

b. Dependent Variable: Perkembangan Psikologis Siswa $(\mathrm{Y})$

\section{Uji Multikolinearitas}


Dari tabel hasil uji multikolinearitas diperoleh nilai VIF pada variabel media internet adalah 1 yang berarti kurang dari 10 dan Tolerance adalah 1 yang berarti lebih dari 0,100 sehingga kesimpulannya tidak terjadi permasalahan multikolinearitas antar variabel independen pada model regresinya.

Tabel. Hasil Uji Multikollinearitas Coefficients $^{\mathrm{a}}$

\begin{tabular}{|c|l|c|c|}
\hline \multicolumn{2}{|c|}{} & \multicolumn{2}{c|}{$\begin{array}{c}\text { Collinearity } \\
\text { Statistics }\end{array}$} \\
\cline { 2 - 4 } \multicolumn{2}{|c|}{ Model } & Tolerance & VIF \\
\hline 1 & $\begin{array}{l}\text { Pengaruh Media } \\
\text { Internet }(\mathrm{X})\end{array}$ & 1.000 & 1.000 \\
\hline
\end{tabular}

a. Dependent Variable: Perkembangan

Psikologis Siswa (Y)

\section{Pengujian Hipotesis 1}

Tabel Hasil Analisis Korelasi

\section{Correlations}

\begin{tabular}{|c|c|c|c|}
\hline & & $\begin{array}{l}\text { Pengaruh } \\
\text { Media } \\
\text { Internet } \\
(\mathrm{X})\end{array}$ & $\begin{array}{c}\text { Perkembangan } \\
\text { Psikologis } \\
\text { Siswa }(Y)\end{array}$ \\
\hline \multirow{4}{*}{$\begin{array}{l}\text { Pengaruh } \\
\text { Media Internet } \\
\text { (X) }\end{array}$} & Pearson & 1 & $.201^{*}$ \\
\hline & Correlation & & \\
\hline & $\begin{array}{l}\text { Sig. (2- } \\
\text { tailed) }\end{array}$ & & .045 \\
\hline & $\mathrm{N}$ & 100 & 100 \\
\hline \multirow{4}{*}{$\begin{array}{l}\text { Perkembangan } \\
\text { Psikologis } \\
\text { Siswa (Y) }\end{array}$} & Pearson & $.201^{*}$ & 1 \\
\hline & Correlation & & \\
\hline & $\begin{array}{l}\text { Sig. (2- } \\
\text { tailed) }\end{array}$ & .045 & \\
\hline & $\mathrm{N}$ & 100 & 100 \\
\hline
\end{tabular}

*. Correlation is significant at the 0.05 level (2-tailed).

Berdasarkan hasil analisis korelasi pada tabel diketahui bahwa nilai $r$ adalah 0,201 yang nilainya lebih besar bila dibandingkan $\mathrm{r}$ table yang bernilai 0,1654, maka dapat dikatakan Ho ditolak dan $\mathrm{Ha}$ diterima, berarti ada hubungan antara media internet dengan perkembangan psikologis siswa MTS di Tanjung Pinang sehingga dapat dibuktikan kebenaran dari hipotesis yang diajukan.

\section{Pengujian Hipotesis 2}

\section{Regresi linier sederhana}

Tabel Hasil analisis regresi linier sederhana

\begin{tabular}{|c|c|c|c|c|c|}
\hline $\begin{array}{c}\text { Variabe } \\
\mathbf{1}\end{array}$ & $\begin{array}{c}\text { Persamaan } \\
\text { Regresi }\end{array}$ & $\begin{array}{c}\mathbf{F} \\
\text { hit } \\
\text { un }\end{array}$ & $\begin{array}{c}\text { Pro } \\
\text { babi } \\
\text { litas }\end{array}$ & $\begin{array}{c}\text { T } \\
\text { hi } \\
\text { tu } \\
\mathbf{n}\end{array}$ & $\begin{array}{c}\text { Interp } \\
\text { retasi }\end{array}$ \\
\hline g & \\
\hline terhadap & $\begin{array}{c}56,818+ \\
\text { Y }\end{array}$ & $\begin{array}{c}4, \\
12\end{array}$ & $\begin{array}{c}5,04 \\
5<0,\end{array}$ & $\begin{array}{c}1, \\
9\end{array}$ & $\begin{array}{c}\text { Linier } \\
\text { dan }\end{array}$ \\
8 & 4 & 05 & $\begin{array}{c}\text { Ho di } \\
\text { tolak }\end{array}$ \\
\hline
\end{tabular}

Berdasarkan hasil analisis di atas dapat dibuat persamaan garis regresi sebagai berikut:

$\mathrm{Y}=56,818$

$+0,103 \mathrm{X}$

$\mathrm{Y}=56,818$ artinya bahwa nilai Constanta sebesar 56,818 yang berarti bila variabel independen yaitu media internet bernilai 0 , maka perkembangan psikologis siswa MTS di Tanjung Pinang akan bernilai 56,818 satuan.

$\mathrm{X}=\quad 0,103$ artinya apabila terjadi peningkatan penggunaan media internet sebesar satu satuan maka perkembangan psikologis siswa MTS di Tanjung Pinang akan mengalami peningkatan sebesar 0,103 satuan.

\section{Menghitung koefisien korelasi sederhana}

Berdasarkan hasil analisis regresi linier dapat diketahui besarnya koefisien korelasinya yaitu 0,201 dan nilai korelasi 
tersebut kurang dari 0,1654 (dari $\mathrm{r}_{\text {table }}$ dengan melihat taraf signifikasi 5\% dengan sampel 100). Maka antara media internet terhadap perkembangan psikologis siswa MTS di Tanjung Pinang terdapat hubungan positif dan signifikan. Kesimpulannya dari hipotesis yang diajukan telah terbukti kebenarannya.

\section{Uji Ketepatan Model (Uji F)}

Uji F digunakan apabila ingin mengetahui apakah variabel bebas yaitu pengaruh media internet secara simultan memberi kontribusi terhadap variabel terikat yaitu perkembangan psikologis siswa MTS di Tanjung Pinang. Hasil uji $F$ diperoleh nilai $F_{\text {hitung }}$ sebesar 4,124 dengan nilai probabilitas 0,045 lebih kecil dari 0,05. Dengan demikian, pengaruh media internet secara simultan memberikan hubungan yang signifikan terhadap perkembangan psikologis siswa MTS di Tanjung Pinang.

\section{Koefisien determinasi $\left(\mathbf{R}^{2}\right)$}

Besarnya hubungan antara variabel media internet dengan variabel perkembangan psikologis siswa ditunjukan oleh angka $r^{2}$ sebesar 0,201. Dalam mencari besaran kontribusi pengaruh media internet (X) terhadap perkembangan psikologis siswa (Y) dengan menggunakan rumus determinasi yaitu hasil dari kuadrat koefisien korelasi dikali $100 \%$, maka $\mathrm{KP}=(0,201)^{2} \times 100 \%$ $=0,040=4,0 \%$. Berdasarkan rumus determinasi tersebut maka dapat diketahui besaran kontribusi pengaruh media internet terhadap perkembangan psikologis siswa MTS adalah sebesar 4,0 $\%$. Angka ini menunjukan kontribusi pengaruh media internet dalam meningkatkan perkem-bangan psikologis siswa adalah rendah, sedang-kan sisanya yaitu sebesar 96,0\% dipengaruhi oleh variabel lain.

Dari gambaran analisis data di atas, terdapat pengaruh signifikan antara media internet terhadap perkembangan psikologis siswa MTS di Tanjung Pinang. Ada hubungan positif antara antara media internet terhadap perkembangan psikologis siswa MTS di Tanjung Pinang, yang ditunjukkan dengan besarnya korelasi antara variable $\mathrm{X}$ dengan $\mathrm{Y}$ yaitu sebesar 0,201 >0,1654 ( $\mathrm{r}$ table dengan taraf signifikasi 5\% dan besarnya sampel 100). Maka terdapat hubungan yang positif antara media internet terhadap perkembangan psikologis siswa MTS di Tanjung Pinang, yang berarti variabel tersebut signifikan. Berarti semakin baik pengunaan media internet maka akan diikuti pula tingginya perkembangan psikologis siswa yang dapat dicapai, sebaliknya semakin rendah pengunaan media internet, maka diikuti pula rendahnya perkembangan psikologis siswa MTS di Tanjung Pinang yang dicapai.

\section{KESIMPULAN}

Hubungan media internet terhadap perkembangan psikologis siswa MTS di Tanjung Pinang, dapat disimpulkan bahwa tidak terdapat hubungan signifikan, yang ditunjukkan dari nilai $\mathrm{r}$ hitung yaitu 0,201 $\leq 0,2499$ yang menurut J. Supranto berarti tidak ada pengaruh sama sekali, dan juga dari hasil $\mathrm{t}$ hitung $(2,031)>t$ tabel $(1,98472)$ pada taraf signifikansi $5 \%$ yang berarti hipotesis penelitian/hipotesis kerja $\left(\mathrm{H}_{1}\right)$ diterima. 
Walaupun hubungan media internet terhadap perkembangan psikologis siswa MTS di Tanjung Pinang tidak berpengaruh sama sekali, namun koefisien korelasi bernilai positif (dihitung dari nilai $\mathrm{r}^{2}$ hitung $\mathrm{x} 100 \%=0,04$ atau $4 \%$ ) yang artinya terjadi hubungan positif antara media internet $(\mathrm{X})$ dengan perkembangan psikologis siswa (Y), dimana semakin naik X maka Y juga akan semakin meningkat.

\section{Saran}

1. Penelitian ini memberikan informasi bahwa pengaruhnya hanya sebesar 4 $\%$ saja dari media internet terhadap perkembangan psikologi siswa. Persentase-nya kecil tetapi hal ini menunjukkan bahwa perkembangan psikologis siswa masih banyak dipengaruhi oleh faktor lain. Oleh karena itu, diharapkan dalam penelitian selanjutnya untuk lebih mencari lagi faktor yang mempengaruhi perkembangan psikologis selain yang diteliti dalam penelitian ini.

2. Hendaknya orang tua selalu memberikan perhatian penuh kepada anak-anaknya terutama dalam penggunaan game online yang marak dilakukan anak-anak sekarang ini, yang berakibat dapat mempengaruhi prestasi belajarnya. Keberhasilan seorang anak dalam belajar juga ditentukan oleh seberapa besar kepedulian para orang tua dalam memperhatikan pendidikan anaknya, karena perhatian mereka dapat meningkatkan semangat didalam diri mereka.
3. Para siswa hendaknya mengetahui bahwa media internet juga dapat memberikan dampak positif terhadap prestasi belajar mereka, sehingga diharapkan keseriusan dan kesungguhannya untuk mengikuti pelajaran disekolah. Serta lebih giat lagi belajar dengan lebih baik agar dapat termotivasi dan dalam memecahkan permasalahnya sendiri pada materi soal pelajaran-pelajaran dengan lebih baik, sehingga dapat menghasilkan prestasi belajar dan citacita yang baik pula. Disarankan kepada siswa agar dapat meningkatkan penggunaan media internet sebagai sumber belajar sehingga minat belajar siswa juga akan semakin tinggi, dibantu dengan dukungan dan peran guru-guru agar tetap memberikan teladan dan senantiasa membimbing para siswa dalam pemanfaatan media internet sebagai sumber belajar. Dengan cara mengadakan bimbingan dan pengarahan dalam penggunaan media internet sebagai sumber belajar tambahan bagi para siswa.

\section{DAFTAR PUSTAKA}

Abror, Abdurrohman, Psikologi Pendidikan, Yogyakarta: Tiara Wacana, 1993.

Arikunto, Suharsimi., Prosedur Penelitian: Suatu Pendekatan Praktik, Jakarta: Rineka Cipta, 2013.

Bungin, Burhan, Metodologi penelitian Kuantitatif, Jakarta: Penerbit Kencana Prenada Media Grup, 2009. 
Creswell, John W., Research design : qualitative, quantitative, and mixed methods approaches, 4th ed, California : SAGE Publications, Inc, 2014.

Dalyono, M., Psikologi Pendidikan (Komponen MKDK), Semarang: PT.Rineka Cipta, 1996.

Danang S., Analisi Regresi Dan Uji Hipotesis, Yogyakarta: Caps, 2011.

Ekomadyo, Ike Junita, Prinsip Komunikasi Efektif untuk meningkatkan minat belajar anak, Bandung : Simbiosa Rekatma Medi, 2005.

Fauzi, Ahmad, Psikologi Umum, Bandung: CV Pustaka Setia, Cet.ke-2, 2004.

Hanif, Yulingga Nanda., Wasis Himawanto, Statistik Pendidikan, Yogyakarta: Penerbit

Deepublish, 2017.

Indriantoro dan Supomo, Bambang., Metodologi Penelitian Bisnis Untuk. Akuntansi dan Manajemen, Yogyakarta: BPFE, 1999. .

J. Moleong, Metodologi Penelitian Kualitatif, Bandung: PT Remaja Rosdakarya Offset, 2007.

J.R. Raco, Metode Penelitian Kualitatif Jenis, Karakter dan Keunggulannya, Jakarta: Penerbit PT Gramedia Widiasarana Indonesia, 2010.

Julius H. Lolombulan, Statistika Bagi Peneliti Pendidikan,

Yogyakarta:Penerbit Andi, 2017.

Kartono, Kartini, Psikologi Umum, Bandung: Mandar Maju, Cet. III , 1996.

Luhst, K.M., Real Estate Valuation. USA: Principles Aplication, 1997.
Mappiare, Andi, Psikologi Remaja, Surabaya: Penerbit Usaha Nasional, t.t .

Matthew B. Miles., and A., Michael Huberman, Qualitative Data Analysis, London:SAGE Publications Ltd, 1994.

Poerwadarminta, W.J.S., Kamus Umum Babasa Indonesia, Jakarta: Balai Pustaka, 1976.

Pososoewarno, Belajar dan Faktor-Faktor Psikologi Pembelajaran, Semarang: Toha Putra, 1997.

Priyono, Metode Penelitian Kuantitatif, Sidoarjo: Zifatama Publishing, 2016.

Purwanto, M. Ngalim, Ilmu Pendidikan Teoritis dan Praktis, Bandung: PT. Remaja Rosda Karya, 1995.

Rahim, H Muhammad Yusuf, 'Pemanfaatan ICT Sebagai Media Pembelajaran Dan Informasi Pada UIN Alauddin Makassar', 6 (2011), 9 $<$ https://doi.org/10.24252/.v6i2. 1408>

Ratna Y., Dany H., Teori-Teori Dasar Psikologi Pendidikan, Jakarta: Penerbit P.T Prestasi Pustaka, 2011.

Roqib, M., Ilmu Pendidikan Islam: Pengembangan Pendidikan Integratif Di Sekolah, Keluarga Dan Masyarakat (Yogyakarta: LKiS, 2009)

Rusydi Ananda, Muhammad Fadhli, Statistik Pendidikan Teori Dan Praktike Dalam Pendidikan, Medan:CV.Widya Puspita, 2018.

Rutoto, Sabar., Pengantar Metedologi Penelitian, Kudus:FKIP Universitas Muria Kudus, 2007. 
Shaleh, Abdul Rahman, dkk., Psikologi Suatu Pengantar (Dalam Perspektif Islam), Jakarta: Prenada Media, 2004.

Sirait, Sheilla Chairunnisyah, 'Tanggung Jawab Pemerintah untuk Memberikan Pendidikan Kepada Anak Terlantar dalam Perspektif Undang-Undang Perlindungan Anak' $<$ https://doi.org/10.31219/osf.i $\mathrm{o} / 75 \mathrm{tp} 2>$

Slameto, Belajar dan Faktor-Faktor yang Mempengarubinya. Jakarta: Rineka Cipta, 2003.

Soemanto, Wasty, Psikologi Pendidikan (Landasan Kerja Kepemimpinan Pendidikan), Jakarta: Rineka Cipta, 1990.

Sudarsono, Kenakalan Remaja, Jakarta: Penerbit Rineka Cipta, 1990.

Sugiono, Metode Penelitian Kuantitatif Kualitataif dan R\&D, Bandung:Alfabeta, 2011.

Sugiono, Metode Penelitian

PendidikanPendekatan Kuantitaif, Kualitatif Dan R\&D (Bandung: Alfabeta, 2008)

Sugiyono, Memahami Penelitian Kualitatif, Bandung: Alfabeta, 2009.

Sugiyono, Metode Penelitian Pendidikan Pendekatan Kuantitaif, Kualitatif dan R\&D, Bandung:Alfabeta, 2008.
Sukamadinata, Nana Syaodih., Metode Penelitian Pendidikan, Bandung:Remaja Rosdakarya, 2007.

Sukardi, Bimbingan dan Penyuluhan, Surabaya: Usaha Nasional, 1987.

Sumanto, Statistika Terapan, Yogyakarta: Caps, 2014.

Sumarsono, Sonny, Metode Riset Sumber Daya Manusia. Yogyakarta: Graha Ilmu, 2004.

Suryabrata, Sumadi, Psikologi Pendidikan, Jakarta: Rajawali Pers, 1998.

Suyanto, Agus, Psikologi Umum, Bandung: Remaja Rosdakarya, 2001.

Syah, Muhibbin, Psikologi Belajar, Jakarta: Penerbit Logos,1999.

Thoha, M. Chabib, dkk., PBM - PAI di Sekolah, Yogyakarta: Pustaka Pelajar Offset, 1998.

Tim Penyusun Kamus Pusat Pengembangan dan Pembinaan Bahasa, Kamus Besar Bahasa Indonesia, Jakarta: Balai Pustaka, 1990.

W. Gulo, Metodelogi Penelitian, Jakarta: Penerbit Pt Gramedia Widiasarana Indonesia, 2000.

Wahy, Hasbi, 'Keluarga Sebagai Basis Pendidikan Pertama dan Utama', Jurnal Ilmiah Didaktika, 12.2 (2012) $<$ https://doi.org/10.22373/jid.v $12 \mathrm{i} 2.451>$ 